OPEN ACCESS

Edited by:

Rosa Del Campo,

Ramón y Cajal Institute for Health

Research, Spain

Reviewed by:

chen $\mathrm{Yu}$,

Duke University, United States Carolina Gutiérrez, Hospital Universitario Quirónsalud

Madrid, Spain

*Correspondence:

Weitao Song

wtsong1980@126.com

Specialty section:

This article was submitted to

Mucosal Immunity,

a section of the journal

Frontiers in Immunology

Received: 20 October 2021

Accepted: 19 January 2022

Published: 23 February 2022

Citation:

Li Y, Jeong J and Song W (2022)

Molecular Characteristics and

Distribution of Adult Human

Corneal Immune Cell Types.

Front. Immunol. 13:798346.

doi: 10.3389/fimmu.2022.798346

\section{Molecular Characteristics and Distribution of Adult Human Corneal Immune Cell Types}

\author{
Yanxiu $L^{1,2,3}$, Joyce Jeong ${ }^{4}$ and Weitao Song ${ }^{1,2,3 *}$ \\ ${ }^{1}$ National Clinical Research Center for Geriatric Diseases, Xiangya Hospital of Central South University, Changsha, China, \\ ${ }^{2}$ Eye Center of Xiangya Hospital, Central South University, Changsha, China, ${ }^{3}$ Hunan Key Laboratory of Ophthalmology, \\ Changsha, Hunan, China, ${ }^{4}$ College of Literature, Science, and the Arts, University of Michigan, Ann Arbor, MI, United States
}

Background: The limbus is located at a 2-mm-wide area between the bulbar conjunctiva and the cornea and has been suggested to be the niche of corneal epithelial stem cells and immune cells. Like the skin and intestines, the cornea is also an important mucosal surface, and immune cells on the cornea play critical roles in immune surveillance to ensure barrier surface homeostasis and protection from various environmental damage and infections. Single-cell RNA sequencing (scRNA-seq) analysis of protein tyrosine phosphatase receptor type $\mathrm{C}$ positive $\left(\mathrm{PTPRC}^{+}\right)$hematopoietic cells from the corneal limbus could provide a single cell atlas of all the immune cell subsets.

Methods: We performed single-cell RNA sequencing to generate transcriptomic profile for 804 sort-purified hematopoietic cells from the corneal limbus of three healthy donors.

Results: Our analysis identified a primary transcriptomic pattern for multiple immune cell subtypes, including naive $T$ cells, antiviral effector $C D 8^{+} T$ cells, and innate immune cells such as IDO1 ${ }^{+}$mature regulatory dendritic cells (mregDCs), macrophages, monocytes, and basophils in the human corneal limbus.

Conclusion: Overall, single-cell transcriptomic analysis of limbal immune cells suggested the possible contribution of these cells on the adaptive and innate immune response of the human cornea.

Keywords: single-cell transcriptome, corneal immune cells, MregDC, antiviral CD8+ ${ }^{+}$cells, chemotactic

\section{INTRODUCTION}

Ocular surface diseases represent a huge medical need and are a substantial burden to many families (1). Due to the limited treatments for these diseases, investigation of the immune system of the ocular surface is crucial. The ocular surface, which comprises the cornea, limbus conjunctiva, and tear film, plays a key role in the visual system. Among these structures, the cornea is an avascular and transparent anterior surface that, together with the lens focus, allows light to be transmitted to the retina for visual processing (2). Like other mucosal surfaces, the cornea is the surface between the inner tissue and the external environment. It is responsible for protecting the eyes against microbes through innate and adaptive immune systems. The cornea has five distinctive layers, and the corneal limbus is considered an important niche of epithelial cells and immune cells on the 
ocular surface (3). Generally, the physical barrier formed by corneal epithelial cells can prevent pathogens from invading, while the flow of tears along with blinking washes pathogens away. Most importantly, the immune cells on the human cornea provide crucial mucosal immune response to prevent infections and damage.

Human and animal studies have observed altered immune cell distributions or functions in particular eye diseases, such as dry eye and eye allergies (4-7). The ocular surface, like other mucosal tissues, can recruit a variety of immune cells to render protection and homeostatic regulation (8, 9). However, dysfunction of the immune cells on the ocular surface would cause disruption of the corneal epithelial barrier function and ocular surface homeostasis $(7,10,11)$. Therefore, ocular surface immune profiling studies are important to understand ocular surface homeostasis and related diseases. So far, the immune cell types on the cornea of mice have been covered and investigated well. T cells, dendritic cells (DCs), macrophages, mast cells, natural killer cells, $\gamma \delta \mathrm{T}$ cells, and innate lymphoid cells (ILCs) have been investigated on murine cornea (12). However, the present knowledge surrounding corneal immune cells has been primarily limited to murine data, while the composition of immune cells on the human cornea requires more investigation. Due to the rich distribution of capillaries and lymphatic vessels that serve as the entry and exit portals for various immune cells, the corneal limbus is home to immune cells that reside in both the central and peripheral corneal regions (13). In the present study, to better investigate the immune cell types on the human cornea, we performed single-cell RNA sequencing(scRNA-seq) to generate transcriptomic profile for sort-purifiedhematopoietic cells from the corneal limbus of three healthy donors. Unbiased analyses identified seven immune cell types, including innate and adaptive immune cell types. This transcriptomic map of healthy human corneal immune cells can be utilized to better understand the immune response and regulation of the human cornea and help lead toward potential cellular and immunotherapy approaches. Furthermore, transcriptomic information can provide functional insight into the mechanisms of diseases such as viral infections, wound repair, and autoimmune diseases like allergies.

\section{MATERIALS AND METHODS}

\section{Human Samples and Single-Cell Isolation}

The collection of human corneal tissue was approved by the Ethics Committee of Xiangya Hospital. Fresh corneal tissue was peeled gently from three healthy adults using surgical forceps under a stereoscope. To isolate the corneal limbus, the central cornea was carefully removed. After isolating the corneal limbus tissues, we dissociated the tissues and obtained single-cell suspensions based on a previous protocol (14). The corneas were briefly chopped in the media and then digested using collagenase A, dispase II, and DNAse I at $37^{\circ} \mathrm{C}$ for $20 \mathrm{~min}$. The cell suspension was then sorted for live PTPRC ${ }^{+}$cells using a FACSAria III cell sorter (BD Biosciences, Franklin Lakes, NJ, USA) at $4^{\circ} \mathrm{C}$ into 1.5 -ml DNA low-binding Eppendorf tubes containing medium. Sorted purified samples were collected and pelleted for processing with 10X Genomics v2.

\section{Genomics scRNA-seq and Data Analysis}

Single cells suspended in phosphate-buffered saline (PBS) were loaded into a single-cell instrument from the 10X Genomics system. A barcoded cDNA library was constructed using SingleCell 3' mRNA Kit (v2, 10X Genomics). On the Illumina NovaSeq 6000 platform, all libraries (paired-end) were sequenced after passing quality tests. The $10 \mathrm{X}$ Genomics single-cell transcriptome sequencing data were integrated from the pooled cells of three donors and processed with the Cell Ranger Single Cell software suite version 1.3 (https://support. 10xgenomics.com) as described previously (15). The output data were analyzed using the SeqGeq genomic tool version 9.0 (FlowJo, LLC, Ashland, OR, USA). Principal component analysis (PCA) reduction (15 dimensions) was performed, followed by an unbiased $t$-distributed stochastic neighbor embedding ( $t$-SNE) dimensionality reduction. We then performed clustering with a $k$-means filtering of $k=57$ to cluster the cells into seven populations based on the variability in the PCA. The PhenoGraph algorithm (16) was used to identify the distinct ILC progenitor clusters. The seven clusters identified by PhenoGraph were overlaid onto the $t$-SNE map. The Cluster Explorer plug-in was used to characterize the immunophenotype of each cluster. Mean cluster transcript expression plots and expression heatmaps of differentially expressed genes were acquired by conducting the Color Mapping program. Gene Ontology (GO) (molecular function) and Kyoto Encyclopedia of Genes and Genomes (KEGG) pathway enrichment analyses were performed using Metascape (http://metascape.org) (17) and Reactome (https://reactome.org).

\section{Flow Cytometry Analysis and Reagents}

For the validation of individual markers, the cells were analyzed on a NovoCyte flow cytometer (Agilent Technologies, Santa Clara, CA, USA). Hematopoietic cells were isolated as PTPRC (anti-human CD45 and QA17A19) cells using a FACSAria III cell sorter (BD Biosciences). All the antibodies used in this study were from BioLegend (San Diego, CA, USA), unless specified otherwise: anti-human CD3 (UCHT1), anti-human CD8 (SK1), anti-human CD4 (A161A1), anti-human IFN- $\gamma$ (MD-1), antihuman granzyme B (GB11), anti-human granzyme A (CB9), anti-human CD96 (NK92.39), anti-human CD74 (LN2), antihuman CCR7 (G043H7), anti-human IDO1 (V50-1886; BD Biosciences), anti-human HLA-A, HLA-B, and HLA-C (W6/ 32), anti-human HLA-DR (L243), anti-human HLA-DQ (HLADQ1), anti-human CD164 (67D2), anti-human IL-10 (JES3-19F1), anti-human CXCL16 (22-19-12), anti-human TGF- $\beta 1$ (TW4-9E7; BD Biosciences), anti-human perforin 1 (DG9; antibodies-online Inc., Pottstown, PA, USA), antihuman IL-32 (373821; R\&D Systems, Minneapolis, MN, USA), and anti-human CXCL2 (rabbit IgG polyclonal; biorbyt, Cambridge, UK). Anti-human CXCR6 monoclonal antibody and recombinant human CXCL16 were purchased from R\&D System. For intracellular cytokine staining, freshly isolated cells were stained with surface markers and then reactivated for $4 \mathrm{~h}$ 
with $10 \mathrm{ng} / \mathrm{ml}$ phorbol myristate acetate (PMA) and $1 \mu \mathrm{M}$ ionomycin (Sigma, St. Louis, MO, USA) prior to fixation and permeabilization with cytokine staining. The data were then analyzed using FlowJo version 10 (TreeStar) and GraphPad Prism.

\section{Chemotaxis Assay}

Human corneal T-cell migration was evaluated using a 24-well Transwell plate (5.0- $\mu \mathrm{m}$ pore size; Corning, Corning, NY, USA) as described previously (18). Freshly sorted purified corneal $\mathrm{CD}^{+} \mathrm{T}$ cells were washed once with RPMI 1640 medium and then placed in $100 \mu \mathrm{l}$-cell medium in the top chamber of the Transwell plate with or without the addition of $1 \mu \mathrm{g} / \mathrm{ml}$ of antihuman CXCR6 antibody. The bottom chamber of the Transwell plate contained chemokine CXCL16 (100 ng/ml) or the supernatant from the $\mathrm{CD}_{164^{+}}$corneal innate immune cell culture medium $(600 \mu \mathrm{l})$. After $90 \mathrm{~min}$ incubation at $37^{\circ} \mathrm{C}$ in a $5 \% \mathrm{CO}_{2}$ atmosphere, the top chamber was removed and the number of $\mathrm{T}$ cells that had migrated into the bottom chamber was counted using flow cytometry. Migration rate was determined by calculating the percentage of input cells that migrated into the lower chamber.

\section{Statistical Analysis}

For statistical analysis of normally distributed continuous variables between two groups, an unpaired Student's $t$-test was used. Significance between multiple groups was determined using one-way ANOVA. A $p$-value $<0.05$ was considered to be significant in this study. All data were presented as the mean \pm standard error of the mean (SEM).

\section{Available Data}

Processed data from scRNA-seq are available at the ArrayExpress database in the European Nucleotide Archive EMBL-EBI, with accession ID E-MTAB-11027.

\section{RESULTS}

\section{Identification of Immune Cell Populations in the Corneal Limbus}

To determine the transcriptome profiles of all immune cell subsets in the cornea, we decided to perform transcriptomic analysis on the sorted purified hematopoietic cells from the human corneal limbus. As our focus is primarily on immune cells, we used PTPRC, a marker for hematopoietic cells, to distinguish immune cells from other cell types such as epithelial and stromal cells in the cornea. We performed fluorescence-activated cell sorting (FACS) to isolate PTPRC ${ }^{+}$ hematopoietic cells from the corneal limbus after removal of the corneal endothelium and central cornea. Human adult corneas were excised from three healthy male donors (18, 50, and 78 years old). The collected cells were dissociated and subjected to the $10 \mathrm{X}$ Genomics platform for scRNA-seq (Figures 1A, B). Transcriptome profiling of 804 cells was performed after passing quality control. These cells were embedded, and seven major cell clusters were revealed using unsupervised $t$-SNE and unbiased clustering (Figure 1C). Clusters 1-7 were determined to comprise macrophages, naive T cells, double-negative (DN) T cells, $\mathrm{CD}^{+} \mathrm{T}$ cells, monocytes, basophils, and DCs, respectively, based on specific marker genes (Figure 1D). For instance, macrophages and monocytes were identified by $C D 68$, while DCs were identified by the high expressions of the HLA subtypes and CD74. The percentage of each immune cell cluster was determined (Figure 1C). The data suggested that innate immune cells occupied around half of the clusters, while the other half was identified as T lymphocytes. Specifically, $\mathrm{CD}^{+} \mathrm{T}$ cells (19.1\%) and macrophages (16.5\%) were the predominant subsets in adaptive and innate immune cells, respectively. To gain more insight into the function of corneal immune cells, a total of 1,217 most differentially expressed genes were used to generate enriched ontology clusters with Metascape (Figures 1E, F). Two major clustering trees were visualized, and biological pathways such as response to cytokine, hormone, and lipid were associated with inflammatory response. Another putative biological function is cellular movement and development regulation. Overall, the genes expressed on the corneal immune cells were enriched in inflammatory response and cellular development. In addition, pathway analysis using Reactome also supported these differentially expressed genes being enriched in multiple immune response pathways such as cytokine regulation, MHC class II antigen presentation, and neutrophil degranulation (Supplementary Figures S1A, B).

\section{Antiviral Effector CD8 ${ }^{+} \mathrm{T}$ Cells Are the Predominant T-Lymphocyte Subset}

Three clusters of $\mathrm{T}$ lymphocytes were identified by the high expressions of specific T-lymphocyte markers: $C D 3 E, C D 3 D$, and LCK (Figure 2A). However, B lymphocytes were barely detected on the corneal limbus (Supplementary Figure S1C). Among the clusters, three T-lymphocyte subsets-naive T cells, DN T cells, and $\mathrm{CD}^{+} \mathrm{T}$ cells-were identified based on specific markers (Figures 2A-C). In line with a previous study (19), CD4 mRNA was hardly detected on the corneal limbus, according to our scRNA-seq data. However, it has been reported that the mRNA expression of CD4 did not match the protein expression (20), and detectable protein levels of CD4 were confirmed by flow cytometry (Figure 2D). Interestingly, the antiviral capacity of the CD8 T cell subset was identified based on the high expressions of the activation markers CD69 and Lag3 and the antiviral genes GZMA, GZMB, PRF1, IFNG, and IL32 (Figures 2B, C). Additionally, corneal limbal $\mathrm{CD} 8^{+} \mathrm{T}$ cells expressed the surface receptor $C D 96$, which has been considered as a co-stimulatory receptor that enhances $\mathrm{CD} 8^{+} \mathrm{T}$-cell activation in humans (21). We subsequently confirmed the expressions of IFN- $\gamma$, granzyme A, granzyme B, IL-32, perforin 1, and CD96 from the corneal limbal $\mathrm{CD}^{+} \mathrm{T}$ cells based on protein level by flow cytometry (Figure 2E). Therefore, we proposed that $\mathrm{CD}^{+} \mathrm{T}$ cells specifically act as functional effectors in controlling viral spread on the cornea. Another important T-lymphocyte subset is naive T cells, which expressed CD28, CD27, and IL7R (Figures 2A, B). Furthermore, naive $\mathrm{T}$ cells also specifically expressed an 


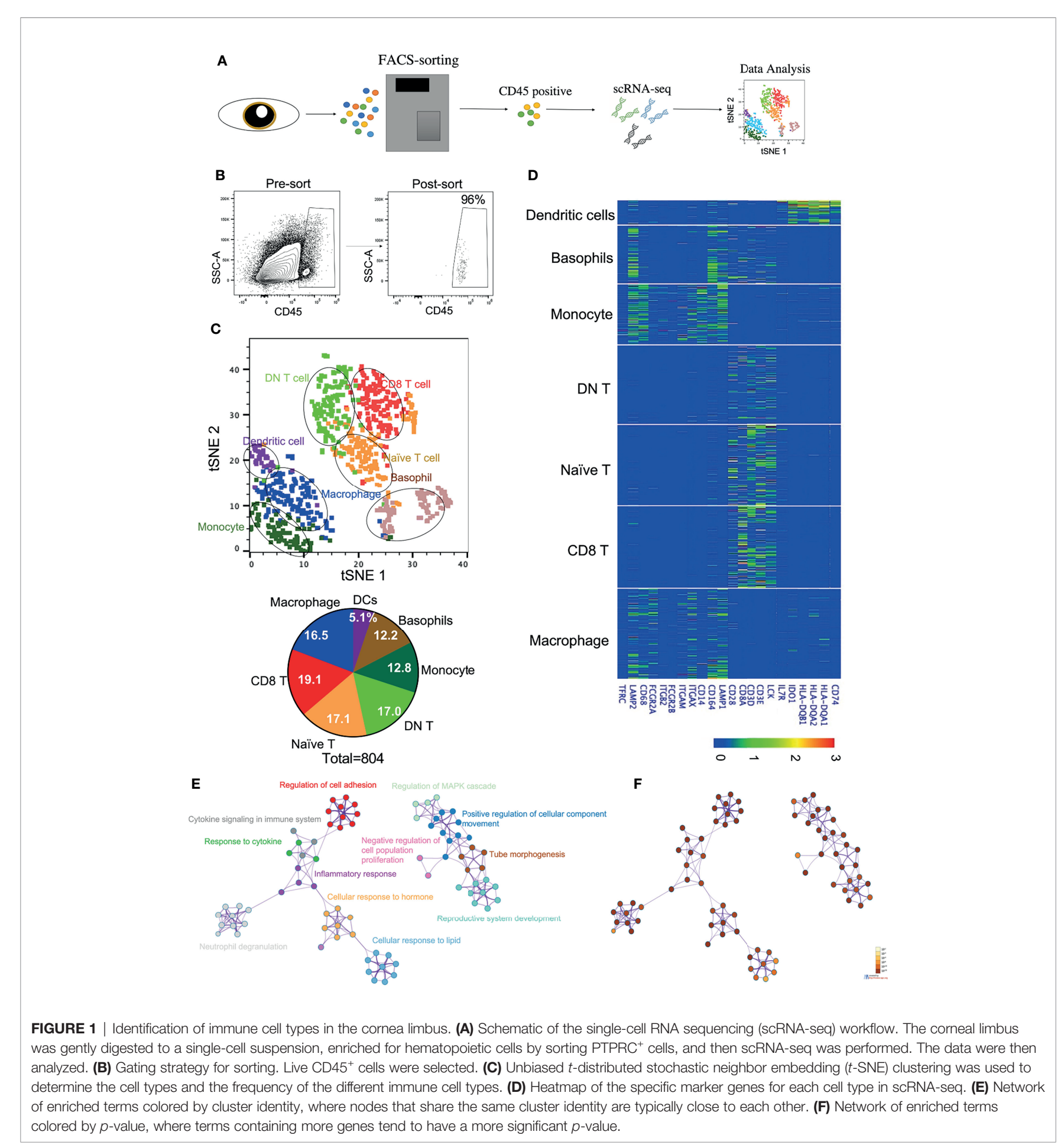

important pioneer chromatin modifier, BATF, which is an essential transcriptional factor in regulating the differentiation of effector $\mathrm{CD}^{+} \mathrm{T}$ cells (22). Therefore, we suggested that corneal limbal $\mathrm{BATF}^{+}$naive $\mathrm{T}$ cells could differentiate into antiviral effector $\mathrm{CD}^{+} \mathrm{T}$ cells. Unexpectedly, we also found a DN T-cell subset located in the corneal limbus that contained a few $\gamma \delta \mathrm{T}$ cells (Supplementary Figure S1C), which requires further investigation in the future. In summary, we proposed that corneal limbal CD8 T cells are the major subset of immune cells preventing the corneal tissue from becoming virally infected by producing cytokines and cytotoxic granules, including IFN- $\gamma$, granzyme A, granzyme B, IL-32, and perforin 1. Furthermore, effector $\mathrm{CD}^{+} \mathrm{T}$ cells are likely to be differentiated from BATFexpressing naive $\mathrm{T}$ cells. 

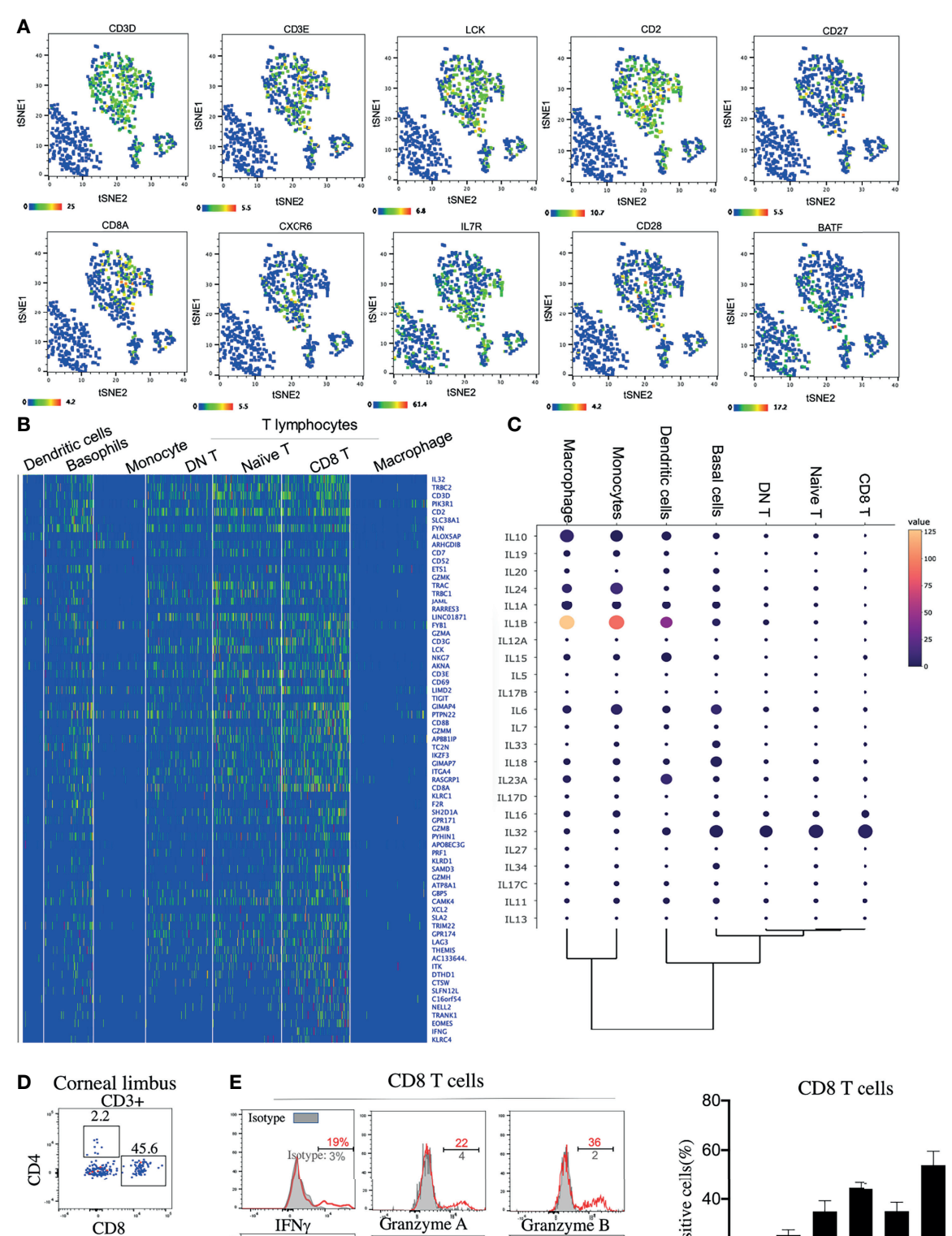

E
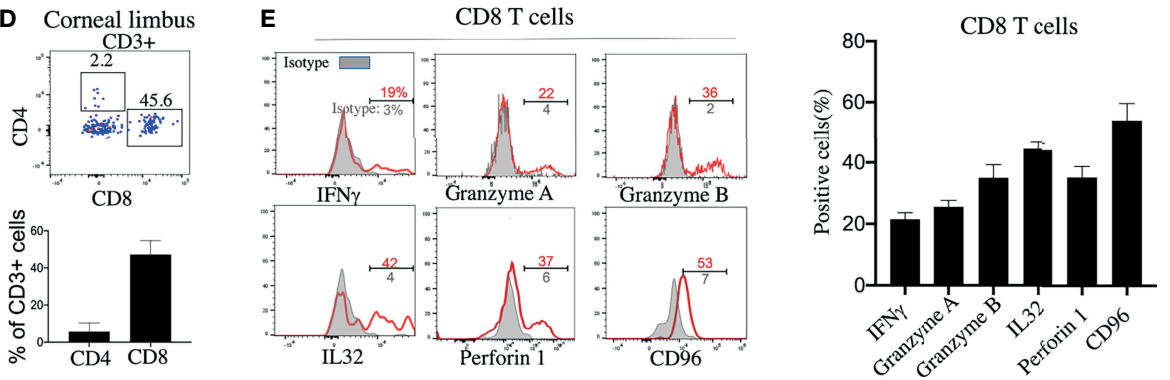

FIGURE 2 | Antiviral effector CD8 ${ }^{+}$T cells are a predominant lymphocyte subset on the cornea. (A) Feature $t$-distributed stochastic neighbor embedding ( $t$-SNE) plot showing the expressions of marker genes enriched on corneal T cells. (B) Heatmap of the top expressed genes in the corneal T-cell subsets. (C) Dot plot showing the expressions of genes of the different cytokines (rows) on each cluster (columns). The color of each dot represents the average log-scaled expression of each gene across all cells of a given cluster. The size of the dot represents the fraction of cells in the cluster in which transcripts for that gene were detected. (D) Expressions of CD8 and CD4 proteins on corneal CD3 ${ }^{+} \mathrm{T}$ cells by flow cytometry $\mathbf{( E )}$ Expressions of selected cytokines and surface proteins on corneal CD8 ${ }^{+} \mathrm{T}$ cells by flow cytometry.

\section{Anti-Inflammatory Macrophages and Monocytes Recruit Naive T Cells by Secreting CXCL16}

Accordingly, four distinct clusters of innate immune cellsmonocytes, macrophages, basophils, and DCs-were observed and annotated through specific markers (Figures 1D, 3A, and Table 1). Among these cell subsets, basophils were identified by the high expressions of Lamp1/2 and CD164. Macrophages expressed specific genes such as CD14, CD68, and FCGR2A/B. Interestingly, various chemokines from the $\mathrm{C}-\mathrm{X}-\mathrm{C}$ motif ligand 


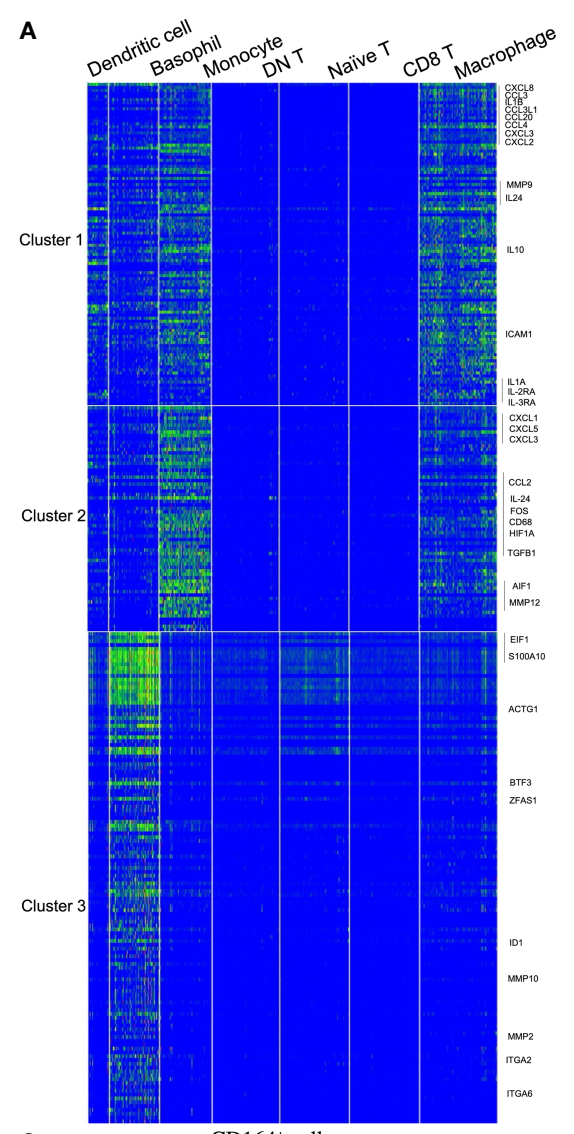

C

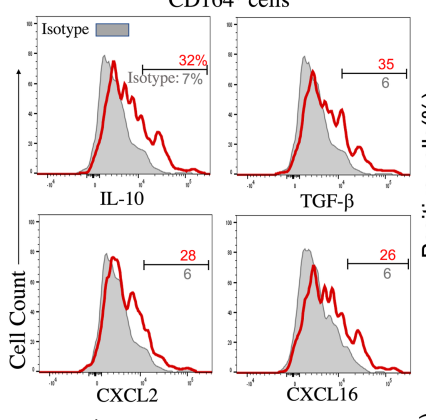

D

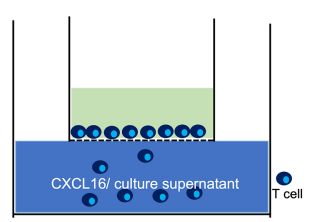

B
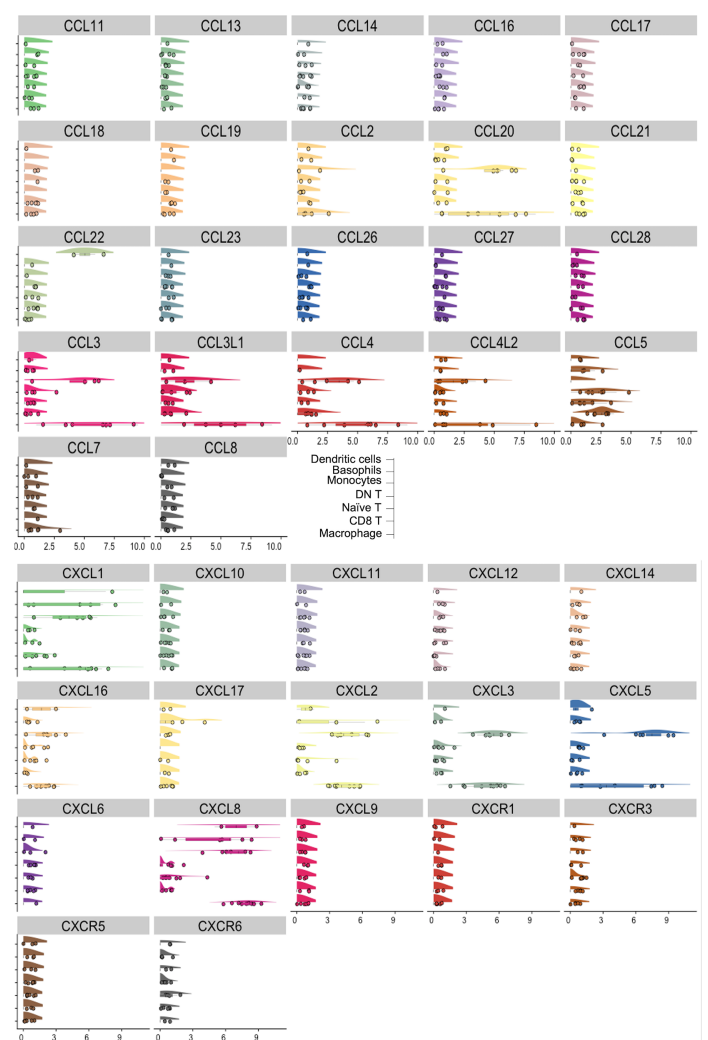

E
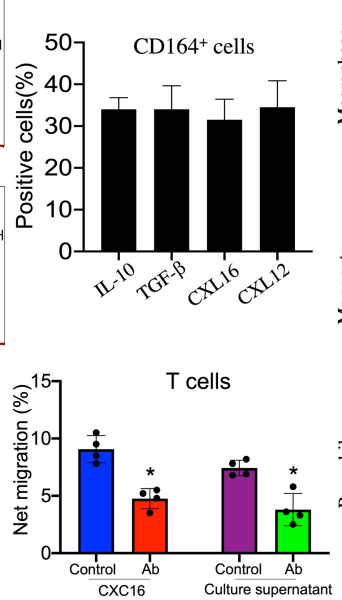

FIGURE 3 | Immunoregulatory macrophages and monocytes recruit naive T cells by secreting CXCL16. (A) Heatmap of the top expressed genes in corneal macrophages, basophils, and monocytes. (B) Violin plot of the expressions of chemokine ( $\mathrm{C}-\mathrm{X}-\mathrm{C}$ motif) ligands and chemokine (C-X-C motif) receptors in each cluster. (C) Expressions of IL-10, TGF- $\beta$, CXCL16, and CXCL12 on CD164 ${ }^{+}$corneal innate immune cells by flow cytometry. (D) Chemotactic activity of corneal CD3+ T cells to $100 \mathrm{ng} / \mathrm{ml} \mathrm{CXCL16}$ or the cell culture supernatant was determined with the Transwell migration system. (E) Pathway enrichment analysis of the differentially expressed genes in corneal macrophages, basophils, and monocytes. *Significant differences ( $<<0.05$, Student's t test) from control groups.)

family, including CXCL1, CXLC2, CXCL3, CXCL5, CXCL8, and CXCL16, were expressed on these innate immune cell types, especially monocytes and macrophages (Figures 3A, B). Among the CXCL chemokine family, CXCL16 is the ligand for CXCR6 which is also highly expressed on corneal naive $\mathrm{T}$ cells. It has been reported that CXCL16 could induce the chemoattraction of $\mathrm{CXCR}^{+}$human skin T cells (23), so we were eager to investigate whether corneal innate immune cells could recruit naive $\mathrm{T}$ cells 
TABLE 1 | Gene list of each cluster from Figure 3A.

\begin{tabular}{|c|c|c|c|c|c|}
\hline Cluster 1 & Cluster 2 & Cluster 3 & Cluster 1 & Cluster 2 & Cluster 3 \\
\hline CCL2O & CXCL5 & KRT17 & $I L 1 A$ & KYNU & MMP1 \\
\hline CCL3 & CD14 & S100A2 & ZEB2 & $O A Z 1$ & $A K R 1 C 1$ \\
\hline CCL4L2 & CTSD & PERP & DUSP4 & MAFB & KLF5 \\
\hline IL1B & THBS1 & TACSTD2 & RCAN1 & DUSP1 & PHLDA2 \\
\hline EREG & FCER1G & KRT14 & WTAP & SERF2 & CLDN7 \\
\hline CXCL8 & RNASE1 & SFN & SLC7A11 & & SULT2B1 \\
\hline CXCL3 & MT1G & SPRR2A & VIM & & $L D H A$ \\
\hline CXCL2 & $P P B P$ & EMP1 & GADD45B & & SERPINB5 \\
\hline INHBA & S100A8 & MMP3 & PLA2G7 & & PPP1R14B \\
\hline MMP9 & TYROBP & ADIRF & MPC2 & & KRT13 \\
\hline CREG1 & CTSB & MAL2 & SNAPC1 & & RPS8 \\
\hline PTGS2 & CXCL3 & SPRR1B & CD68 & & YВXЗ \\
\hline C15orf48 & $F T L$ & MMP12 & IL2RA & & TSC22D1 \\
\hline ACSL1 & SLC11A1 & SLPI & MPZL1 & & SELENOM \\
\hline IER3 & NAMPT & S100A14 & $D A B 2$ & & C6orf132 \\
\hline$A B C A 1$ & MS4A7 & ANXA1 & $K Y N U$ & & RPS13 \\
\hline HSP90AA1 & CDЗ०0E & $C D 24$ & MIR3945HG & & $S L C 2 A 1$ \\
\hline FNIP2 & LAPTM5 & LYPD3 & SMS & & DENND2C \\
\hline OGFRL1 & HIF1A & KRT19 & PFKFB3 & & C19orf33 \\
\hline socs3 & CD68 & IGFBP3 & DNAJB6 & & HMGA1 \\
\hline PDE4DIP & CAPG & GPRC5A & TNIP3 & & KRT12 \\
\hline PLAUR & $D M X L 2$ & CSTB & TNFAIP3 & & CD59 \\
\hline FTL & $\angle C P 1$ & LMO7 & MMP14 & & KRT6B \\
\hline ICAM1 & C5AR1 & SPRR2D & PILRA & & RPS24 \\
\hline NFKBIA & S100A4 & $A K R 1 C 2$ & MAP4K4 & & PLAU \\
\hline IL24 & $L Y Z$ & MT2A & PDPN & & HSP9OAB1 \\
\hline PSAP & FOS & ELF3 & SERPINA1 & & GIPC1 \\
\hline АТР13АЗ & MT1F & S100A16 & $K L F 6$ & & $A Q P 3$ \\
\hline ETS2 & TMEM176B & $C L U$ & GRAMD1A & & NACA \\
\hline NRP2 & PLIN2 & HSPB1 & ASAH1 & & RPL37A \\
\hline BCAT1 & FCGRT & S100A6 & EGR1 & & PRDX5 \\
\hline DSE & SPl1 & S100A11 & MS4A7 & & ISG2O \\
\hline$P D E 4 B$ & TUBB & $E Z R$ & TCF4 & & SDCBP2 \\
\hline CD83 & VCAN & ANXA2 & SPP1 & & CAV1 \\
\hline FABP5 & $P K M$ & RND3 & MCL1 & & RPS5 \\
\hline SLC16A10 & GAPDH & SERPINE2 & DOCK4 & & $R P L 7$ \\
\hline PPP1R15A & $L Y N$ & TPT1 & $A R L 4 C$ & & COL17A1 \\
\hline NINJ1 & ASAH1 & $D C N$ & TRAF1 & & RPL26 \\
\hline CTSZ & ATP6V1F & CAMK2N1 & PTPN1 & & $R P L 7 A$ \\
\hline CD63 & PILRA & ID1 & SEMAGB & & RPS18 \\
\hline SAMSN1 & GPNMB & LGALS3 & ATP6V1F & & DST \\
\hline STC1 & TNFRSF1B & CRYAB & OTUD1 & & RPLP1 \\
\hline CTSB & RNF130 & CD55 & GK & & $R P L 8$ \\
\hline SMOX & $A Q P 9$ & NDRG1 & TLR2 & & HEBP2 \\
\hline PLEK & CEBPB & RPL24 & PTPRE & & GGCT \\
\hline
\end{tabular}

TABLE 1 | Continued 
TABLE 1 | Continued

\begin{tabular}{|c|c|c|}
\hline Cluster 1 & Cluster 2 & Cluster 3 \\
\hline$A B L 2$ & & BTF3 \\
\hline PPIF & & RPL18 \\
\hline MAP2K3 & & RPL36 \\
\hline NR4A2 & & $R A P 2 B$ \\
\hline GYPC & & RPL15 \\
\hline SQSTM1 & & ElF1 \\
\hline EHD1 & & PPP1CB \\
\hline$A S P H$ & & ANXA11 \\
\hline CFLAR & & TNFRSF12A \\
\hline THBD & & RPS12 \\
\hline SAT1 & & CEBPD \\
\hline SLC5A3 & & PTPN13 \\
\hline JUN & & ZFAS1 \\
\hline MIR155HG & & $R H O D$ \\
\hline$A K R 1 B 1$ & & RPS3A \\
\hline LHFPL2 & & ITGA6 \\
\hline CSF2RA & & RPL21 \\
\hline NANS & & RPS28 \\
\hline MARCKS & & FXYD3 \\
\hline RILPL2 & & RPS7 \\
\hline PID1 & & RPS23 \\
\hline ATP6VOB & & SDC1 \\
\hline SERPINB9 & & $D R A P 1$ \\
\hline DRAM1 & & S100A13 \\
\hline CSF2 & & CSTA \\
\hline TNFAIP8 & & HOPX \\
\hline FTH1 & & SCEL \\
\hline GPR183 & & $M A L L$ \\
\hline CCL18 & & $R P L P O$ \\
\hline CD109 & & MMP10 \\
\hline TALDO1 & & RPL11 \\
\hline TNFRSF4 & & RPL35 \\
\hline UBE2D1 & & MMP2 \\
\hline MAFB & & $K R T 15$ \\
\hline LITAF & & RACK1 \\
\hline CEBPB & & RPL41 \\
\hline TNIP1 & & RPL37 \\
\hline MMP19 & & VDAC2 \\
\hline SDCBP & & RPS27A \\
\hline IQGAP1 & & RPL35A \\
\hline GPAT3 & & LAMB3 \\
\hline ATP6V1B2 & & RPL10A \\
\hline MGLL & & RPL14 \\
\hline$G L A$ & & RPL4 \\
\hline ATP8B4 & & RPL19 \\
\hline MT1X & & PPDPF \\
\hline THBS1 & & $M A L$ \\
\hline PDIA3 & & GUK1 \\
\hline RGCC & & RPL13 \\
\hline EIF5 & & RPL30 \\
\hline CRIM1 & & FOSL1 \\
\hline IVNS1ABP & & DSC3 \\
\hline GLUL & & ZFAND5 \\
\hline \multirow[t]{10}{*}{$\angle P X N$} & & RPL22 \\
\hline & & RPL3 \\
\hline & & RPS15 \\
\hline & & RPL12 \\
\hline & & RPL32 \\
\hline & & RPL39 \\
\hline & & IL6 \\
\hline & & RPL18A \\
\hline & & NPM1 \\
\hline & & RPL23A \\
\hline
\end{tabular}

TABLE 1 | Continued

\begin{tabular}{|c|c|c|}
\hline Cluster 1 & Cluster 2 & Cluster 3 \\
\hline & & CAV2 \\
\hline & & RPL29 \\
\hline & & RPL27 \\
\hline & & RPL9 \\
\hline & & SELENOK \\
\hline & & NNMT \\
\hline & & SLK \\
\hline & & RPL27A \\
\hline & & RPL23 \\
\hline & & MUC16 \\
\hline & & RPS10 \\
\hline & & RPL34 \\
\hline & & FAM129B \\
\hline & & $R A N$ \\
\hline & & RPLP2 \\
\hline & & YWHAQ \\
\hline & & CNN3 \\
\hline & & RPS4X \\
\hline & & НЗFЗВ \\
\hline & & SOD3 \\
\hline & & RPS21 \\
\hline & & SERP1 \\
\hline & & MUC22 \\
\hline & & $\angle G A L S L$ \\
\hline & & $P R D \times 1$ \\
\hline & & MYO6 \\
\hline & & RPL6 \\
\hline & & KRT18 \\
\hline & & PFDN2 \\
\hline & & KRT10 \\
\hline & & $\mathrm{CHCHD} 2$ \\
\hline & & RPL13A \\
\hline & & SPINT2 \\
\hline & & SEC61G \\
\hline & & RPS2 \\
\hline & & $R P S 14$ \\
\hline & & $A B / 3 B P$ \\
\hline & & RPS15A \\
\hline & & RPS25 \\
\hline & & CCDC85B \\
\hline & & USP53 \\
\hline & & $A F D N$ \\
\hline & & CALM2 \\
\hline & & ARF4 \\
\hline & & LUM \\
\hline & & EEF1A1 \\
\hline & & $K L F 4$ \\
\hline & & PITX1 \\
\hline & & CLTA \\
\hline & & RAC1 \\
\hline & & ACTN4 \\
\hline & & RPS3 \\
\hline & & EEF1B2 \\
\hline & & $\mathrm{CDH} 1$ \\
\hline & & MT-ND4L \\
\hline & & COL6A2 \\
\hline & & CYCS \\
\hline & & NEAT1 \\
\hline & & RIOK3 \\
\hline & & RPS11 \\
\hline & & $R P S A$ \\
\hline & & CAPN2 \\
\hline & & LAMC2 \\
\hline
\end{tabular}


TABLE 1 | Continued

\begin{tabular}{|c|c|c|}
\hline \multirow[t]{64}{*}{ Cluster 1} & Cluster 2 & Cluster 3 \\
\hline & & RPS19 \\
\hline & & CST3 \\
\hline & & RPL38 \\
\hline & & IGFBP4 \\
\hline & & EPS8L1 \\
\hline & & EEF2 \\
\hline & & TNFAIP6 \\
\hline & & NQO1 \\
\hline & & SLC25A3 \\
\hline & & TMSB10 \\
\hline & & PKP1 \\
\hline & & $R P L 28$ \\
\hline & & FАM৪ЗА \\
\hline & & LMAN1 \\
\hline & & POLR1D \\
\hline & & MYL12B \\
\hline & & COX7A1 \\
\hline & & CLMP \\
\hline & & ECM1 \\
\hline & & GOLGA4 \\
\hline & & $R A B 11 A$ \\
\hline & & SDF2L1 \\
\hline & & IGFBP2 \\
\hline & & PPL \\
\hline & & RPS9 \\
\hline & & RPS26 \\
\hline & & TGM1 \\
\hline & & RPS29 \\
\hline & & YWHAE \\
\hline & & PRNP \\
\hline & & CCND1 \\
\hline & & SLC39A14 \\
\hline & & RPL36AL \\
\hline & & RAB11FIP1 \\
\hline & & CNBP \\
\hline & & TPM4 \\
\hline & & RTN4 \\
\hline & & SOX4 \\
\hline & & PDLIM4 \\
\hline & & ADGRF1 \\
\hline & & ACTB \\
\hline & & NUPR1 \\
\hline & & $U B C$ \\
\hline & & SET \\
\hline & & YWHAZ \\
\hline & & $B Z W 1$ \\
\hline & & HES1 \\
\hline & & HNRNPA1 \\
\hline & & HERPUD1 \\
\hline & & COX7A2 \\
\hline & & $M T-C Y B$ \\
\hline & & ST14 \\
\hline & & RPL36A \\
\hline & & $N C L$ \\
\hline & & $F A U$ \\
\hline & & PHLDA3 \\
\hline & & SF3B6 \\
\hline & & PAX6 \\
\hline & & ERO1A \\
\hline & & ARF6 \\
\hline & & FST \\
\hline & & TUBB4B \\
\hline & & EIF2S2 \\
\hline
\end{tabular}

TABLE 1 | Continued

\begin{tabular}{|c|c|c|}
\hline Cluster 1 & Cluster 2 & Cluster 3 \\
\hline & & NAP1L1 \\
\hline & & PPIA \\
\hline & & $R P L 10$ \\
\hline & & CEACAM6 \\
\hline & & SDC4 \\
\hline
\end{tabular}

by generating CXCL16. Additionally, all three innate immune cells highly expressed CD164 mRNA, which is generally expressed by granulocytes, based on the scRNA-seq data (Figure 1D). We also confirmed the production of CXCL16 from corneal limbal CD164 ${ }^{+}$cells by flow cytometry (Figure 3C). To conduct an in vitro chemotaxis assay, we placed the recombinant CXCL16 or supernatant from the $\mathrm{CD} 164^{+}$corneal limbal immune cell culture medium in the lower chambers and the sorted purified corneal $\mathrm{CD}^{+} \mathrm{T}$ cells in the presence of isotype or anti-CXCR6 antibody in the upper chambers. The chemotaxis data (Figure 3D) suggested that both recombinant CXCL16 and the cell culture supernatant can attract $\mathrm{T}$ cells from the upper chamber. In addition, blocking CXCR6 using antibodies could significantly inhibit the chemoattraction of $\mathrm{T}$ cells toward the recombinant CXCL16 or the cell culture supernatant in the lower chamber. Therefore, the data indicated that corneal limbal innate immune cells can potentially recruit naive $\mathrm{T}$ cells into the corneal limbus and generate antiviral effector $\mathrm{CD}^{+} \mathrm{T}$ cells downstream. Furthermore, the generation of anti-inflammatory cytokines such as IL-10 and TGF- $\beta$ from monocytes and macrophages indicated that they play an immunoregulatory role in the immune response of the human corneal limbus (Figures 2C and $\mathbf{3 A}, \mathbf{B})$. Wound healing of the cornea is a multistep process with four overlapping but distinct stages: hemostasis, inflammation, proliferation, and remodeling. Corneal limbal macrophages and monocytes produced the chemokines CXCL1, CXCL2, and CXCL8, which are important for the inflammation and proliferation stages of wound healing (Figures 3B, C). Furthermore, both macrophages and monocytes could respond to wounding based on the KEGG pathway and GO annotation analyses (Figure 3E). It also suggested that corneal macrophages, monocytes, and basophils are capable of the degranulation and regulation of cytokine production. Thus, besides attracting naive $\mathrm{T}$ cells, cornea limbal innate immune cells also have the potential to suppress the immune response and aid in wound healing.

\section{Corneal Limbal Dendritic Cells Are IDO1 $^{+}$mregDCs}

DCs comprise the unique cell type among the corneal innate immune cells. Although other immune cells such as macrophages and monocytes could express the major HLA subtypes, such as $H L A-A / B / C / E, H L A-D R A$, and HLA-DRB1, corneal limbal DCs expressed various other subtypes, including $H L A-D P B 1, D P A 1, D Q B 1, D Q A 1 / 2$, and $D M A$ (Figures 4A, B). Therefore, it is suggested that DCs function as the major antigenpresenting cells connecting the innate and adaptive immune 
A

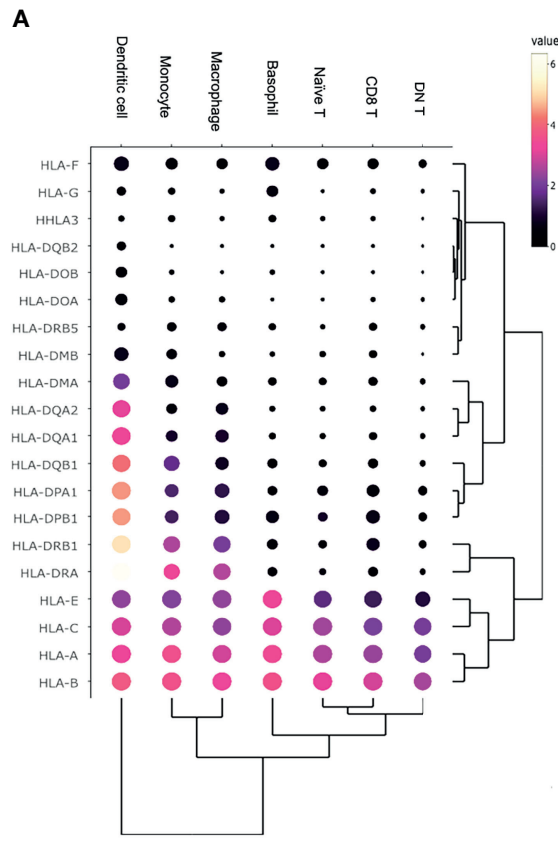

B

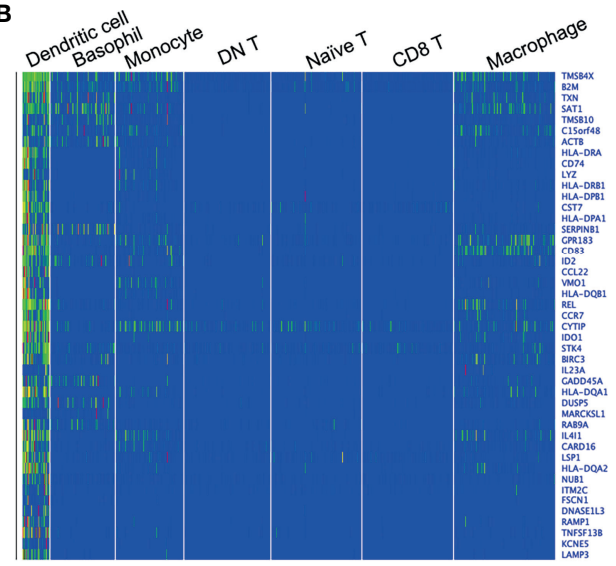

C

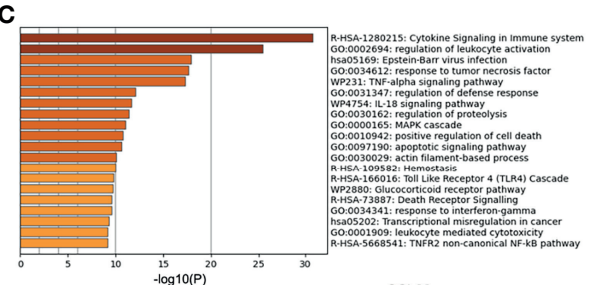

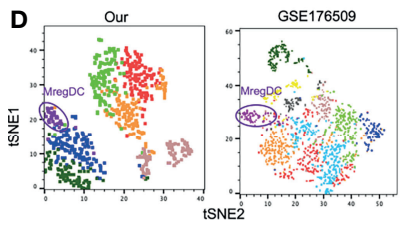
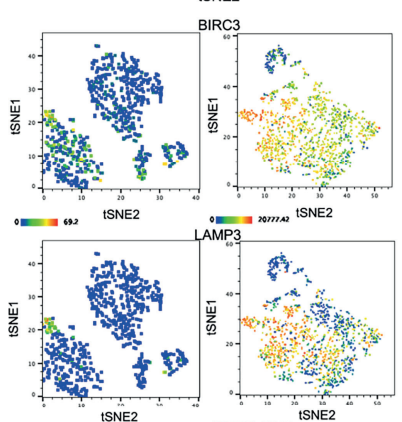

Aำ 20 ma 2 SNE2
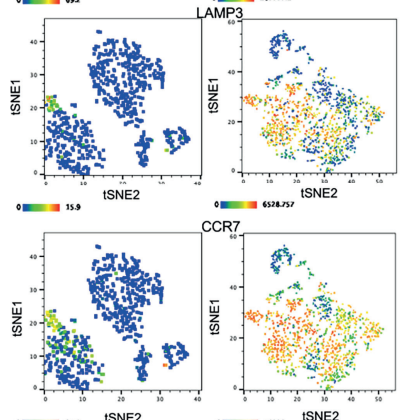

CCR7

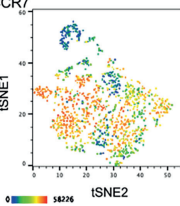

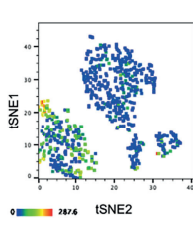

CD74
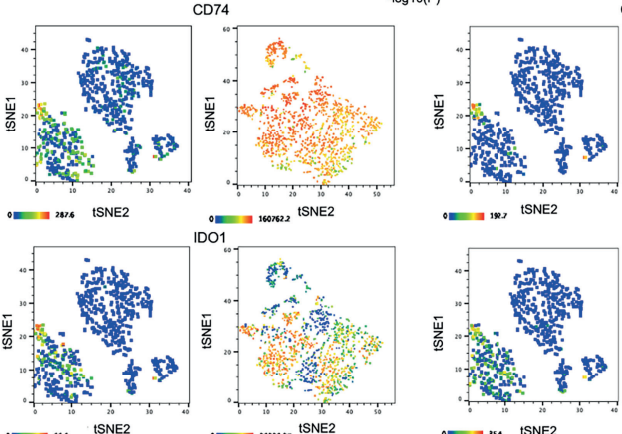

CCL22

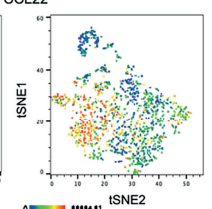

IDO1
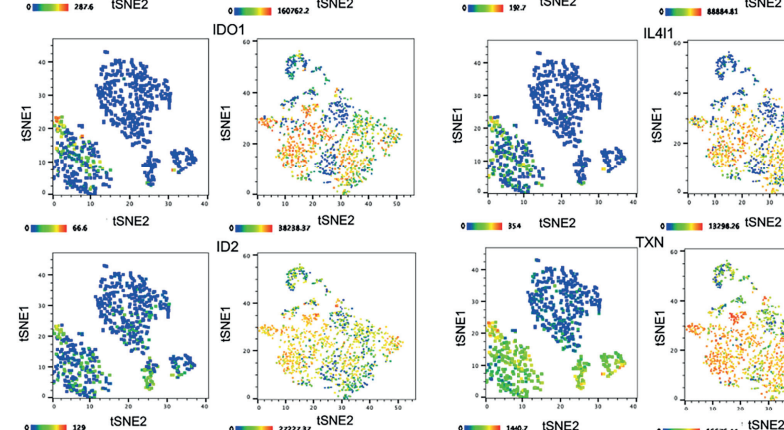

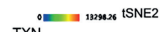
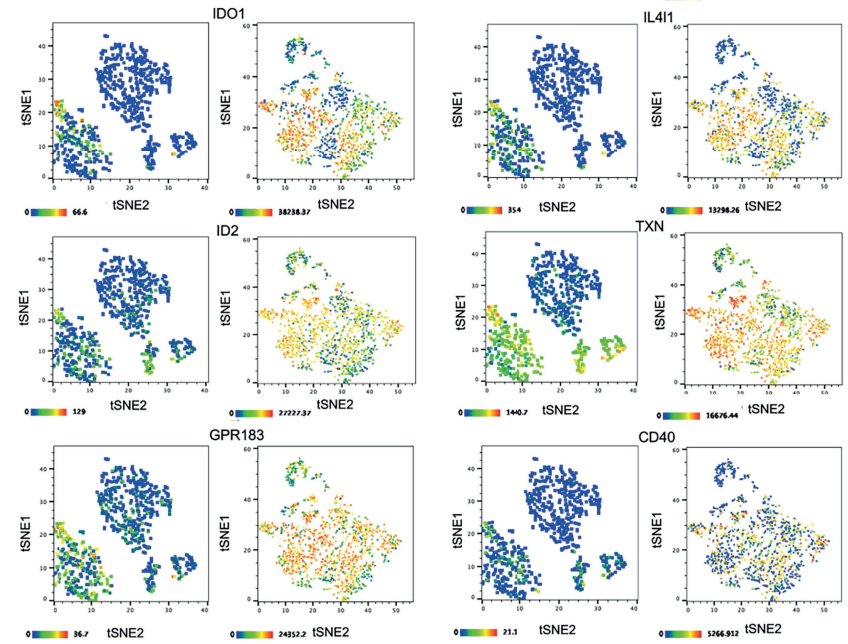

FIGURE 4 | IDO1 ${ }^{+}$mature regulatory dendritic cells (mregDCs) are the major antigen-presenting cells on the cornea. (A) Dot plot showing the expressions of genes of the HLA subtypes (rows) in each cluster (columns). The color of each dot represents the average log-scaled expression of each gene across all cells of a given cluster. The size of the dot represents the fraction of cells in the cluster in which transcripts for that gene were detected. (B) Heatmap of the top expressed genes in corneal dendritic cells. (C) Pathway enrichment analysis of the differentially expressed genes in corneal dendritic cells. (D) The $t$ distributed stochastic neighbor embedding ( $t$-SNE) plot showing comparative expressions of mregDC-specific signature genes from our data and those of Nakamizo et al. (20).

systems on the human cornea. The KEGG pathway and GO annotation analyses were performed by using Metascape and showed that corneal DCs participate in cytokine signaling in the immune system and regulate leukocyte activation (Figure 4C).
Surprisingly, we found that the corneal limbal DCs are mregDCs, which displayed high expressions of the markers LAMP3 and BIRC3 (24) (Figure 4B and Supplementary Figure S2A). This new subset of DCs has recently been identified in human skin 
mucosal tissues. To better compare the mregDCs between the corneal limbus and the skin, we reanalyzed other publicly available skin datasets (GEO accession no. GSE176509) (24) and identified skin mregDCs using the same methods of $t$-SNE analysis and clustering. We found that, except for LAMP3 and $B I R C 3$, both corneal and skin mregDCs highly expressed CCR7, CD74, ID2, GPR183, CCL22, IL4l1, CD40, and TXN (Figure 4D and Supplementary Figure S2). In addition, corneal limbal mregDCs also expressed high levels of the pro-inflammatory cytokines IL1B, IL-15, and IL-23A, which are associated with mucosal inflammation (24). MregDCs have also been found to be involved in cytokine signaling and regulation of leukocyte activation (Figures 2C and 4C, D). The analysis indicated that mregDCs potentially play a pro-inflammatory role in the immune response of the cornea. Interestingly, consistent with recent papers (25), we also found that the mregDCs in both the skin and corneal limbus specifically expressed indoleamine-2,3dioxygenase (IDO1), a counter-regulatory and tolerogenic molecule (Figure 4D). Although there were several subsets of DCs identified in the skin, only one corneal limbal DC subset was detected on the cornea limbus, and this DC subset belongs to mregDCs. Furthermore, corneal limbal mregDCs do not only act as antigen-presenting cells but also participate in regulating immune tolerance by coordinating with other innate immune cells.

\section{DISCUSSION}

On the ocular surface, the cornea is a unique and highly specialized tissue that is avascular and transparent in order to allow light to be transmitted for vision. Recent studies have identified cell types in the cornea using scRNA-seq; however, they primarily paid attention to epithelial and stromal cells, the major cell types in the cornea $(19,25,26)$. In this study, we concentrated on the immune cell types and observed seven distinct immune cell clusters that differed in function. Overall, we reported a primary scRNA-seq analysis of the human corneal innate and adaptive immune cell types, including antiviral effector $\mathrm{CD}^{+} \mathrm{T}$ cells, naive $\mathrm{T}$ cells, and innate immune cells such as $\mathrm{IDO}^{+}$mregDCs, macrophages, monocytes, and basophils, providing a detailed map of corneal immune cell function. It should be noted that, because aging could lead to changes in the immune system, such as the distribution and number of immune cells $(27,28)$, despite using similar numbers of cells from each donor, the wide donor-to-donor age variation could affect the results to a certain extent. We identified subtypespecific transcriptional factors and surface markers for the different immune cell types. Through flow cytometry, but not scRNA-seq, a few $\mathrm{CD}^{+} \mathrm{T}$ cells were detected on the human cornea in a steady state. In addition, human corneal naive T cells highly expressed $B A T F$, which has been proven to be crucial for the differentiation of effector $\mathrm{CD}^{+} \mathrm{T}$ cells in a steady state (22) and during viral infection (29). Therefore, BATF is likely to be an important regulator for the differentiation of naive $\mathrm{T}$ cells into antiviral effector $\mathrm{CD}^{+} \mathrm{T}$ cells in the human cornea. The co- stimulatory receptor CD96 and the activation markers Lag3 and CD69 were highly expressed on $\mathrm{CD}^{+} \mathrm{T}$ cells $(21,30,31)$. Furthermore, several antiviral cytokines and cytotoxic granules, such as IFN- $\gamma$, granzyme A, granzyme B, perforin 1 , and IL-32, were produced by corneal $\mathrm{CD} 8^{+} \mathrm{T}$ cells, which further confirmed that $\mathrm{CD}^{+} \mathrm{T}$ cells in the human cornea have the ability to fight against viruses even at a steady state. Therefore, we believe that $\mathrm{CD}^{+} \mathrm{T}$ cells are a significant immune cell type that prevents virus infection in the human cornea, which is consistent with a previous finding on mouse corneas (32). Furthermore, it has been proven that severe acute respiratory syndrome coronavirus 2 (SARS-CoV-2) was detected on the human cornea $(33,34)$. As is known, $\mathrm{CD}^{+} \mathrm{T}$ cells are crucial to the prevention of SARSCoV-2 infection (35), so it can be considered that corneal CD8 ${ }^{+}$ $\mathrm{T}$ cells may also contribute to protecting the eyes from SARSCoV-2 infection. We also proved that, from in vitro studies, CXCR6-expressing naive $\mathrm{T}$ cells are attracted by the specific chemokine CXCL16 produced by corneal innate immune cell types, including macrophages, DCs, and monocytes. This result indicated that CXCL16 is not only required for the colon's immune system (36) but is also important in maintaining the immune response of the cornea. Because we did not detect regulatory $\mathrm{T}$ cells in the cornea, we were eager to search for other immunoregulatory immune cell types. Interestingly, sequencing and flow cytometry data indicated that macrophages and monocytes are dominant cell types that produce IL-10 and TGF- $\beta$, which are known antiinflammatory cytokines that suppress the immune response. Meanwhile, they also express various chemokine genes such as CCL3, CCL20, CCL4, CC3L1, CCL4L2, CXCL2, CXCL8, and CXCL5. We believe that these innate immune cells can recruit and regulate distinct cell types by generating chemokines. Analyses of KEGG pathway and GO annotation also indicated that macrophages, monocytes, and basophils could degranulate and be involved in wound healing. Another interesting innate immune cell type comprise DCs, the major antigen-presenting cells in the cornea. DCs displayed their ability to present antigens by highly expressing various HLA subtype genes such as HLA$D Q A, H L A-D P A$, and $H L A-D P B$. Recently, researchers have identified a small subset of skin DCs called mregDCs with high expressions of BIRC3, LAMP3, IL15, CD40, and CCR7, and this subset has been thought to be associated with wound healing and the exacerbation of atopic dermatitis $(24,37,38)$. It is surprising to find that corneal DCs also belong to mregDCs, with high expressions of the unique markers BIRC3 and LAMP3. Furthermore, we compared the corneal and skin mregDCs by reanalyzing the data from public scRNA-seq and unexpectedly found that there are high levels of similarity between the mregDCs from these two mucosal tissues. The three major pro-inflammatory cytokine genes expressed on corneal DCs were $I L 1 B, I L-15$, and $I L-23 A$. Consistently, all three cytokines were produced by skin DCs and considered to be associated with atopic dermatitis and psoriasis. Additionally, GO enrichment analysis of the upregulated genes in DCs suggested that corneal DCs participate in cytokine signaling and regulation of leukocyte activation. Consequently, we suggested that the cytokines IL-1 $\beta$, 
IL-15, and IL-23a produced by corneal mregDCs could be crucial to ocular inflammation. Intriguingly, both corneal and skin mregDCs also expressed IDO1, which is a heme-containing enzyme that can suppress T-cell response. Additionally, IDO1expressing DCs may provide an immunoregulatory network by promoting the development of regulatory T cells (39). Therefore, DCs could play a crucial role in maintaining and regulating a dynamic balance between pro- and anti-inflammatory signals.

In summary, the goal of this study was to provide crucial information regarding all the immune cell types located in the adult human cornea limbus. Identification of the different corneal immune cell types using transcriptomic analysis can help in understanding the eye immune network. In addition, this study revealed the genes/pathways of immune cells that could lead to improvements in immunotherapies for corneal disease and wound repair of the corneal limbus.

\section{DATA AVAILABILITY STATEMENT}

The processed data of single-cell RNA-seq are available at the ArrayExpress database in European Nucleotide Archive EMBLEBI with accession ID E-MTAB-11027.

\section{ETHICS STATEMENT}

The studies involving human participants were reviewed and approved by the Ethics Committee of Xiangya Hospital. The patients/participants provided written informed consent to participate in this study.

\section{REFERENCES}

1. Chan CC, Crowston JG, Tan R, Marin M, Charles S. Burden of Ocular Surface Disease in Patients With Glaucoma From Australia. Asia Pac J Ophthalmol (Phila) (2013) 2:79-87. doi: 10.1097/APO.0b013e31828372c2

2. DelMonte DW, Kim T. Anatomy and Physiology of the Cornea. J Cataract Refract Surg (2011) 37:588-98. doi: 10.1016/j.jcrs.2010.12.037

3. Akpek EK, Gottsch JD. Immune Defense at the Ocular Surface. Eye (Lond) (2003) 17:949-56. doi: 10.1038/sj.eye.6700617

4. Reyes NJ, Saban DR. T Helper Subsets in Allergic Eye Disease. Curr Opin Allergy Clin Immunol (2014) 14:477-84. doi: 10.1097/ACI.0000000 000000088

5. Periman LM, Perez VL, Saban DR, Lin MC, Neri P. The Immunological Basis of Dry Eye Disease and Current Topical Treatment Options. J Ocul Pharmacol Ther (2020) 36:137-46. doi: 10.1089/jop.2019.0060

6. Bose T, Lee R, Hou A, Tong L, Chandy KG. Tissue Resident Memory T Cells in the Human Conjunctiva and Immune Signatures in Human Dry Eye Disease. Sci Rep (2017) 7:45312. doi: 10.1038/srep45312

7. Reyes JL, Vannan DT, Eksteen B, Avelar IJ, Rodríguez T, González MI, et al. Innate and Adaptive Cell Populations Driving Inflammation in Dry Eye Disease. Mediators Inflamm (2018) 2018:2532314. doi: 10.1155/2018/ 2532314

8. Gandhi NB, Su Z, Zhang X, Volpe EA, Pelegrino FS, Rahman SA, et al. Dendritic Cell-Derived Thrombospondin-1 Is Critical for the Generation of the Ocular Surface Th17 Response to Desiccating Stress. J Leukoc Biol (2013) 94:1293-301. doi: 10.1189/jlb.1012524

9. St Leger AJ, Desai JV, Drummond RA, Kugadas A, Almaghrabi F, Silver P, et al. An Ocular Commensal Protects Against Corneal Infection by Driving an

\section{AUTHOR CONTRIBUTIONS}

WS conceptualized, acquired funding, and supervised this study. YL performed sample collection, single-cell dissociation, and library preparation. Data were processed, curated, and visualized by YL. YL, JJ and WS drafted the manuscript. All authors contributed to the article and approved the submitted version.

\section{FUNDING}

This study was supported by the National Nature Science Fund of China (81974132), National Key R\&D Program of China (2021YFA1101202), Hunan Provincial Health Commission (20220702839) and National Nature Science Fund of China (81770927).

\section{SUPPLEMENTARY MATERIAL}

The Supplementary Material for this article can be found online at: https://www.frontiersin.org/articles/10.3389/fimmu.2022.798346/ full\#supplementary-material

Supplementary Figure S1 | Supporting data for cluster analysis. (A) Overview of relevant pathways involved in the immune system obtained from Reactome. (B) Most relevant pathways sorted by $p$-value for differentially expressed genes.

(C) Feature t-SNE plot showing expression of other important marker genes.

Supplementary Figure S2 | The expression of DCs signature genes and chemokine receptors. (A) Violin plot of expression of DCs signature genes in each cluster. (B) Violin plot of expression of CC chemokine receptor genes in each cluster.

Interleukin-17 Response From Mucosal Gammadelta T Cells. Immunity (2017) 47:148-58.e145. doi: 10.1016/j.immuni.2017.06.014

10. Palomar APD, Montolío A, Cegoñino J, Dhanda SK, Lio CT, Bose T. The Innate Immune Cell Profile of the Cornea Predicts the Onset of Ocular Surface Inflammatory Disorders. J Clin Med (2019) 8-12(12):2110. doi: 10.3390/ jcm 8122110

11. Stern ME, Calonge M, Niederkorn JY, Pflugfelder SC. Autoimmunity at the Ocular Surface: Pathogenesis and Regulation. Mucosal Immunol (2010) 3:425-42. doi: 10.1038/mi.2010.26

12. Liu J, Li Z. Resident Innate Immune Cells in the Cornea. Front Immunol (2021) 12:620284. doi: 10.3389/fimmu.2021.620284

13. Wu Y, Seong YJ, Li K, Choi D, Park E, Daghlian GH, et al. Organogenesis and Distribution of the Ocular Lymphatic Vessels in the Anterior Eye. JCI Insight (2020) 5:e135121. doi: 10.1172/jci.insight.135121

14. O'Sullivan F. Primary Culture of Cornea-Limbal Epithelial Cells In Vitro. Methods Mol Biol (2020) 2145:29-37. doi: 10.1007/978-1-0716-0599-8_3

15. Spitzer MH, Carmi Y, Reticker-Flynn NE, Kwek SS, Madhireddy D, Martins $\mathrm{MM}$, et al. Systemic Immunity Is Required for Effective Cancer Immunotherapy. Cell (2017) 168:487-502.e415. doi: 10.1016/j.cell.2016. 12.022

16. Levine JH, Simonds EF, Bendall SC, Davis KL, Amir el AD, Tadmor MD, et al. Data-Driven Phenotypic Dissection of AML Reveals Progenitor-Like Cells That Correlate With Prognosis. Cell (2015) 162:184-97. doi: 10.1016/ j.cell.2015.05.047

17. Zhou Y, Zhou B, Pache L, Chang M, Khodabakhshi AH, Tanaseichuk O, et al. Metascape Provides a Biologist-Oriented Resource for the Analysis of Systems-Level Datasets. Nat Commun (2019) 10:1523. doi: 10.1038/s41467019-09234-6 
18. Lim HW, Hillsamer P, Kim CH. Regulatory T Cells can Migrate to Follicles Upon T Cell Activation and Suppress GC-Th Cells and GC-Th Cell-Driven B Cell Responses. J Clin Invest (2004) 114:1640-9. doi: 10.1172/JCI22325

19. Collin J, Queen R, Zerti D, Bojic S, Dorgau B, Moyse N, et al. A Single Cell Atlas of Human Cornea That Defines Its Development, Limbal Progenitor Cells and Their Interactions With the Immune Cells. Ocul Surf (2021) 21:27998. doi: 10.1016/j.jtos.2021.03.010

20. Li J, Zhang Y, Yang C, Rong R. Discrepant mRNA and Protein Expression in Immune Cells. Curr Genomics (2020) 21:560-3. doi: 10.2174/ 1389202921999200716103758

21. Chiang EY, de Almeida PE, de Almeida Nagata DE, Bowles KH, Du X, Chitre AS, et al. CD96 Functions as a Co-Stimulatory Receptor to Enhance CD8(+) T Cell Activation and Effector Responses. Eur J Immunol (2020) 50:891-902. doi: $10.1002 /$ eji.201948405

22. Kurachi M, Barnitz RA, Yosef N, Odorizzi PM, DiIorio MA, Lemieux ME, et al. The Transcription Factor BATF Operates as an Essential Differentiation Checkpoint in Early Effector CD8+ T Cells. Nat Immunol (2014) 15:373-83. doi: $10.1038 /$ ni.2834

23. Gunther C, Carballido-Perrig N, Kaesler S, Carballido JM, Biedermann T. CXCL16 and CXCR6 Are Upregulated in Psoriasis and Mediate Cutaneous Recruitment of Human CD8+ T Cells. J Invest Dermatol (2012) 132:626-34. doi: $10.1038 /$ jid.2011.371

24. Nakamizo S, Dutertre CA, Khalilnezhad A, Zhang XM, Lim S, Lum J, et al. Single-Cell Analysis of Human Skin Identifies CD14+ Type 3 Dendritic Cells Co-Producing IL1B and IL23A in Psoriasis. J Exp Med (2021) 218(9): e20202345. doi: 10.1084/jem.20202345

25. Dou S, Wang Q, Qi X, Zhang B, Jiang H, Chen S, et al. Molecular Identity of Human Limbal Heterogeneity Involved in Corneal Homeostasis and Privilege. Ocul Surf (2021) 21:206-20. doi: 10.1016/j.jtos.2021.04.010

26. Ligocki AJ, Fury W, Gutierrez C, Adler C, Yang T, Ni M, et al. Molecular Characteristics and Spatial Distribution of Adult Human Corneal Cell Subtypes. Sci Rep (2021) 11:16323. doi: 10.1038/s41598-021-94933-8

27. Geiger H, de Haan G, Florian MC. The Ageing Haematopoietic Stem Cell Compartment. Nat Rev Immunol (2013) 13:376-89. doi: 10.1038/nri3433

28. Elyahu Y, Monsonego A. Thymus Involution Sets the Clock of the Aging TCell Landscape: Implications for Declined Immunity and Tissue Repair. Ageing Res Rev (2021) 65:101231. doi: 10.1016/j.arr.2020.101231

29. Chen Y, Zander RA, Wu X, Schauder DM, Kasmani MY, Shen J, et al. BATF Regulates Progenitor to Cytolytic Effector CD8(+) T Cell Transition During Chronic Viral Infection. Nat Immunol (2021) 22:996-1007. doi: 10.1038/s41590-021-00965-7

30. Workman CJ, Rice DS, Dugger KJ, Kurschner C, Vignali DA. Phenotypic Analysis of the Murine CD4-Related Glycoprotein, CD223 (LAG-3). Eur J Immunol (2002) 32:2255-63. doi: 10.1002/1521-4141(200208)32:8<2255:: AID-IMMU2255>3.0.CO;2-A

31. Cella M, Presti R, Vermi W, Lavender K, Turnbull E, Ochsenbauer-Jambor C, et al. Loss of DNAM-1 Contributes to CD8+ T-Cell Exhaustion in Chronic HIV-1 Infection. Eur J Immunol (2010) 40:949-54. doi: 10.1002/ eji.200940234
32. Conrady CD, Zheng M, Stone DU, Carr DJ. CD8+ T Cells Suppress Viral Replication in the Cornea But Contribute to VEGF-C-Induced Lymphatic Vessel Genesis. J Immunol (2012) 189:425-32. doi: 10.4049/ jimmunol.1200063

33. Sawant OB, Singh S, Wright RE 3rd, Jones KM, Titus MS, Dennis E, et al. Prevalence of SARS-CoV-2 in Human Post-Mortem Ocular Tissues. Ocul Surf (2021) 19:322-9. doi: 10.1016/j.jtos.2020.11.002

34. Casagrande M, Fitzek A, Spitzer MS, Püschel K, Glatzel M, Krasemann S, et al. Presence of SARS-CoV-2 RNA in the Cornea of Viremic Patients With COVID-19. JAMA Ophthalmol (2021) 139:383-8. doi: 10.1001/ jamaophthalmol.2020.6339

35. Peng Y, Mentzer AJ, Liu G, Yao X, Yin Z, Dong D, et al. Broad and Strong Memory CD4(+) and CD8(+) T Cells Induced by SARS-CoV-2 in UK Convalescent Individuals Following COVID-19. Nat Immunol (2020) 21:1336-45. doi: 10.1038/s41590-020-0782-6

36. Diegelmann J, Seiderer JH, Niess D, Haller B, Göke HC, Reinecker J, et al. Expression and Regulation of the Chemokine CXCL16 in Crohn's Disease and Models of Intestinal Inflammation. Inflamm Bowel Dis (2010) 16:1871-81. doi: 10.1002/ibd.21306

37. Chen YL, Gomes T, Hardman CS, Vieira Braga FA, Gutowska-Owsiak D, Salimi M, et al. Re-Evaluation of Human BDCA-2+ DC During Acute Sterile Skin Inflammation. J Exp Med (2020) 217(3):e20190811. doi: 10.1084/ jem.20190811

38. He H, Suryawanshi H, Morozov P, Gay-Mimbrera J, Del Duca E, Kim HJ, et al. Single-Cell Transcriptome Analysis of Human Skin Identifies Novel Fibroblast Subpopulation and Enrichment of Immune Subsets in Atopic Dermatitis. J Allergy Clin Immunol (2020) 145:1615-28. doi: 10.1016/ j.jaci.2020.01.042

39. Mellor AL, Munn DH. IDO Expression by Dendritic Cells: Tolerance and Tryptophan Catabolism. Nat Rev Immunol (2004) 4:762-74. doi: 10.1038/ nri1457

Conflict of Interest: The authors declare that the research was conducted in the absence of any commercial or financial relationships that could be construed as a potential conflict of interest.

Publisher's Note: All claims expressed in this article are solely those of the authors and do not necessarily represent those of their affiliated organizations, or those of the publisher, the editors and the reviewers. Any product that may be evaluated in this article, or claim that may be made by its manufacturer, is not guaranteed or endorsed by the publisher.

Copyright $\odot 2022 \mathrm{Li}$, Jeong and Song. This is an open-access article distributed under the terms of the Creative Commons Attribution License (CC BY). The use, distribution or reproduction in other forums is permitted, provided the original author $(s)$ and the copyright owner(s) are credited and that the original publication in this journal is cited, in accordance with accepted academic practice. No use, distribution or reproduction is permitted which does not comply with these terms. 